\title{
Dynamic Changes in Acetylcholine Output in the Medial Striatum During Place Reversal Learning
}

\author{
Michael E. Ragozzino ${ }^{1}$ and Daniel Choi \\ Department of Psychology, Laboratory of Integrative Neuroscience, University of Illinois at Chicago, Chicago, Illinois 60607, USA
}

\begin{abstract}
The present studies explored the role of the medial striatum in learning when task contingencies change. Experiment 1 examined whether the medial striatum is involved in place reversal learning. Testing occurred in a modified cross-maze across two consecutive sessions. Injections of the local anesthetic, bupivacaine, into the medial striatum, did not impair place acquisition, but impaired place reversal learning. The reversal-learning deficit was due to an inability to maintain the new choice pattern following the initial shift. Experiment 2 determined whether changes in acetylcholine $(\mathrm{ACh})$ output occur during the acquisition or reversal learning of a place discrimination. Extracellular $\mathrm{ACh}$ output from the medial striatum was assessed in samples collected at 6-min intervals using in vivo microdialysis during behavioral testing. ACh output did not change from basal levels during place acquisition. During reversal learning, $\mathrm{ACh}$ output significantly increased as rats began to learn the new choice pattern, and returned to near basal levels as a rat reliably executed the new place strategy. The present results suggest that the medial striatum may be critical for flexible adaptations involving spatial information, and that ACh actions in this area enable the shifting of choice patterns when environmental conditions change.
\end{abstract}

There is accumulating evidence that different striatal regions may play distinct roles in learning and memory (Dunnett and Iversen 1982; Brown and Robbins 1989; Pisa and Cyr 1990; Levy et al. 1997; Devan et al. 1999; Eagle et al. 1999). In particular, the medial striatum may be critical for strategy selection when conditions demand a shift in response patterns (Livesey and Muter 1976; Kolb 1977; Thompson et al. 1980; Whishaw et al. 1987; Pisa and Cyr 1990; Ragozzino et al. 2002a,b). Several studies have found that lesions, temporary inactivation, or targeted pharmacological treatments of the medial striatum do not impair acquisition of a visual cue or egocentric response discrimination, but impair reversal learning or extra-dimensional shifts requiring visual cue and egocentric response discriminations (Kirkby 1969; Pisa and Cyr 1990; Ragozzino et al. 2002a,b). This set of results suggests that the medial striatum is critical when conditions demand the flexible use of visual cue and/or egocentric response information.

The medial striatum may also be important for the flexible use of spatial information. Lesions or blockade of NMDA receptors in the medial striatum impair spatial working memory (Dunnett et al. 1999; Smith-Roe et al. 1999). Furthermore, medial striatal lesions decrease the use of a spatial strategy in the Morris water maze (Whishaw et al. 1987; Devan et al. 1999) and large lesions of the striatum, encompassing the medial striatum, impair place reversal learning (Kolb 1977). Moreover, recordings from dorsomedial striatal neurons in the rat show selective firing when the environmental demands are switched in a spatial memory test, requiring a rat to flexibly use different behavioral strategies (Mizumori et al. 2000). Therefore, the medial striatum may enable behavioral flexibility when conditions require the learning or use of spatial information.

Although there is evidence that the medial striatum contributes to behavioral flexibility, unclear are the neurochemical processes in this brain region that support behavioral flexibility. One

\section{'Corresponding author.}

E-MAIL mrago@uic.edu; FAX (312) 413-4122.

Article and publication are at http://www.learnmem.org/cgi/doi/10.1101/ Im.65404. neurotransmitter that may play a key role in facilitating behavioral flexibility is ACh. ACh content in the striatum originates almost entirely from interneurons (Woolf and Butcher 1981; Bolam et al. 1984). Cholinergic interneurons have been shown to fire tonically at a rate that varies from 4 to $9 \mathrm{~Hz}$ (Wilson et al. 1990; Kawaguchi 1993; Aosaki et al. 1994, 1995). Whereas these neurons exhibit correlated firing during learning of a sensorimotor conditioning task (Aosaki et al. 1994), tonically active neurons also become active during the preparatory phase of a Go/No-Go task that demands the flexible shifting between different responses, and when there is a change in task contingencies as well as context (Apicella et al. 1991; Ravel et al. 2001). Despite this electrophysiological evidence, there has not been a direct examination of ACh output in the medial striatum during a test of behavioral flexibility.

To further characterize the role of the medial striatum in behavioral flexibility, the first experiment determined whether medial striatal inactivation affects place acquisition or reversal learning. Experiment 2 measured ACh efflux during the acquisition and reversal learning of a place discrimination.

\section{RESULTS}

\section{Experiment 1. The Effect of Bupivacaine Infusions Into the Medial Striatum on Acquisition and Reversal Learning of a Place Discrimination}

\section{Histology}

The cannula tip placements in Experiment 1 were concentrated in the anterior portion of the dorsal striatum (see Fig. 1). Histological examination indicated that the cannula tips were found in the medial region of the dorsal striatum. The dye injections revealed that the fluid spread ventrolaterally from the injection site. In no cases, did the dye extend into the nucleus accumbens region. Two rats were excluded from the behavioral analyses because of cannula misplacements. One rat had a cannula placement in the corpus callosum and another rat had a cannula placement in the lateral ventricles. 

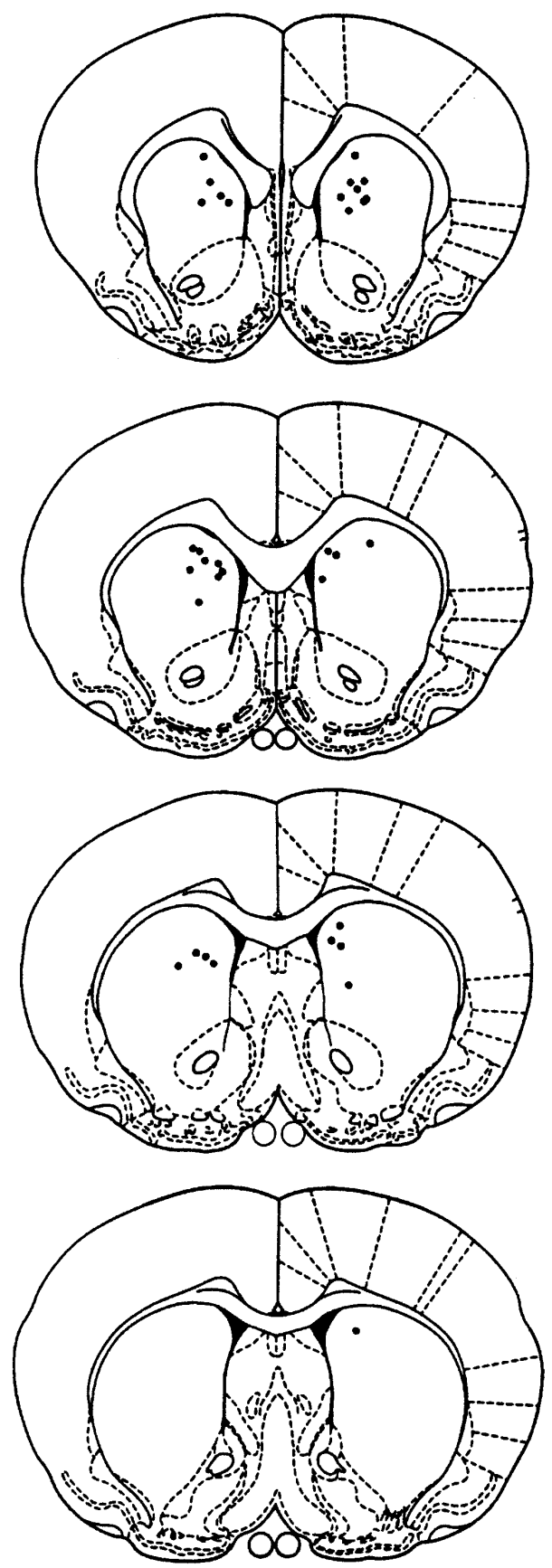

Figure 1 Placement of the cannula tips in the striatum for rats included in the behavioral analyses in Experiment 1. Cannula tips were concentrated in the dorsomedial striatum ranging from 0.2 to 1.7 anterior to bregma. Rat brain sections were modified from the atlas of Paxinos and Watson (1996).

\section{Behavioral Testing}

The results on acquisition and reversal learning of the place discrimination are shown in Figure 2A. Bupivacaine injections into the medial striatum did not impair initial learning compared with that of saline controls. The difference in reaching criterion on the acquisition phase among the groups was not significant, $[\mathrm{F}(2,15)=0.40 ; P>0.05]$. In contrast, the difference in obtaining trials to criterion during reversal learning among the groups was significant, $[\mathrm{F}(2,15)=13.33 ; P<0.01]$. Newman-Keuls tests revealed that the saline-bupivacaine group required significantly more trials to achieve criterion on reversal learning than the saline-saline or bupivacaine-saline groups $\left(P^{\prime} \mathrm{s}<0.05\right)$. The difference in trials to criterion between the saline-saline and bupivacaine-saline groups was not significant $(P>0.05)$.

Figure $2 \mathrm{~B}$ illustrates the pattern of perseverative and regressive errors for the different treatment groups during reversal learning. The difference in perseverative errors among the groups was not significant, $[\mathrm{F}(2,15)=0.16 ; P>0.05]$. However, there was a significant difference in regressive errors among the groups, $[\mathrm{F}(2,15)=9.34 ; P<0.01]$. Newman-Keuls tests indicated that the saline-bupivacaine group made significantly more regressive errors than either the saline-saline or bupivacaine-saline group $\left(P^{\prime} \mathrm{s}<0.05\right)$. The difference in regressive errors between the salinesaline and bupivacaine-saline groups was not significant $(P>0.05)$.

\section{Experiment 2. ACh Output from the Medial Striatum during Acquisition and Reversal Learning of a Place Discrimination}

\section{Histology}

All 10 rats included in the statistical analyses had microdialysis probe placements in the dorsal striatum. As with the cannula tip placements in Experiment 1, the microdialysis probe placements were concentrated in the anterior and medial portions of the dorsal striatum (see Fig. 3).

\section{ACh Output and Behavioral Testing}

ACh output during baseline sampling was similar during the place acquisition and reversal learning sessions. The basal ACh output (mean \pm SEM) from the five samples collected prior to behavioral testing was $542.2 \pm 25.9$ and $519.7 \pm 60.7$ fmoles/ sample in the place acquisition and place reversal-learning sessions, respectively. ACh output during baseline collection from the left and right striata was similar during both test sessions. The basal ACh output collected from the left hemisphere $(n=5)$ in the place acquisition session was $552.4 \pm 38.1$ fmoles/sample. The basal ACh output from the right hemisphere $(n=5)$ in the place acquisition session was $531.9 \pm 35.7$ fmoles/sample. In the place reversal-learning session, the basal ACh output from the left and right hemispheres was $528.9 \pm 116.7$ and $474.4 \pm 35.6$, respectively.

During place acquisition testing, the performance of rats was slightly above chance levels (56.1\%) in the first test block (see Fig. 4A). Performance improved steadily across each subsequent 6-min test block, such that performance improved to $>90 \%$ by the last 6 -min block. Analysis of the percent correct scores across test blocks indicated that there was a significant effect $[\mathrm{F}(4,36)=22.04 ; P<0.01]$, reflecting the improvement in percent correct scores across place acquisition testing. In contrast to the improved behavioral performance across acquisition testing, striatal ACh output did not change during the behavioral test or during the post-test sample collection compared with basal levels $[\mathrm{F}(14,126)=0.89 ; P>0.05$, see Fig. $4 \mathrm{~B}]$.

Figure $5 \mathrm{~A}$ illustrates the behavioral results during the place reversal learning session. In the first 6-min test block, rats initially chose the location that was reinforced during acquisition, but by the end of the first test block, rats began to choose the other location. This pattern is reflected by a percent correct score that was below chance levels (35.4\%). In the subsequent two test blocks, rats performed at chance levels. Performance continued to improve across the final three test blocks, such that rats were obtaining $>90 \%$ accuracy by the final test block. There was a significant effect for test block, $[\mathrm{F}(5,45)=70.57 ; P<0.01]$, again indicating the increase in performance across test blocks. ACh 
A

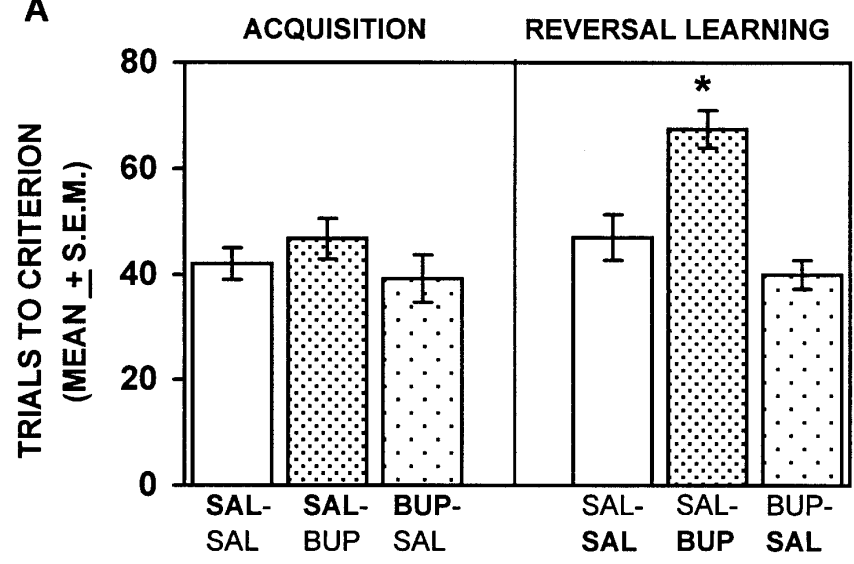

B

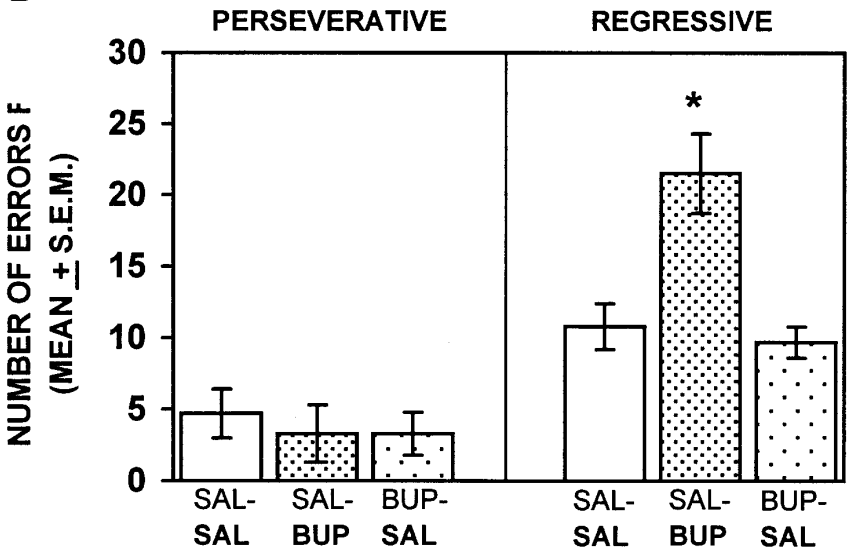

Figure 2 (A) Mean trials to criterion on acquisition and reversal learning of a place discrimination after bilateral infusions of saline or $2 \%$ bupivacaine into the medial striatum. Bupivacaine infusions did not impair acquisition compared with that of saline infusions, but significantly increased the trials to criterion on reversal learning compared with that of saline injections. (SAL) Saline; (BUP) $2 \%$ bupivacaine. The treatment received in a particular phase of testing is represented in bold. $\left(^{*}\right) P<0.05$. (B) Mean number of perseverative and regressive errors during place reversal learning following an injection of either saline or $2 \%$ bupivacaine. Bupivacaine injections increased the number of regressive errors significantly, but not perseverative errors, compared with that following saline infusions. (SAL) Saline; (BUP) $2 \%$ bupivacaine. The treatment received during reversal learning is represented in bold for each group. (*) $P<0.05$

efflux during reversal learning testing did not change initially from basal levels, but subsequently increased starting at the second 6-min block (see Fig. 5B). In subsequent test blocks, ACh efflux remained elevated, but decreased gradually to near basal levels by the last 6-min test block. Analysis of striatal ACh output during the reversal learning session indicated that there was a significant effect, $[\mathrm{F}(15,135)=5.66 ; P<0.01]$. ACh efflux in the first test block was not significantly different from that of baseline levels $(P>0.05)$. ACh efflux at a second test block was elevated significantly compared with baseline levels $(P<0.01)$. ACh output remained significantly elevated above basal levels during the third and fourth test blocks $\left(P^{\prime} \mathrm{s}<0.05\right)$, but ACh output in the last two blocks was not significantly different from that of baseline levels ( $\left.P^{\prime} \mathrm{s}>0.05\right)$.

A previous study found that ACh efflux in the lateral striatum increases during the expression of an egocentric response strategy (Chang and Gold 2003). One possibility is that ACh efflux from the medial striatum became elevated during reversal learning because rats were transiently using an egocentric response strategy. If this were the case, then this behavioral pattern would show up in the type of errors made. Because rats were started from two different arms, directly opposite of each other, then a rat that was predominantly turning in the same direction would only make errors when started from one of the arms. If a rat was not using this type of strategy, then, in theory, the rat should make an equal number of errors from each start arm. A $\chi^{2}$ test was performed on the error pattern in test blocks 2-4 for each rat. Because ACh output was significantly increased in these test blocks, the errors were only examined in these blocks. Four of the 10 rats made significantly more errors from one start arm than the other arm, suggesting these rats were using an egocentric response strategy during test blocks $2-4$. The percent change in ACh output during these test blocks was similar between rats who appeared to be using an egocentric response strategy and those who were not. Specifically, the mean percent change in ACh output during test blocks $2-4$ for the four rats preferentially turning in one direction was $200.0 \pm 43.3$ SEM, and for the other six rats, the mean percent change was $191.3 \pm 15.0$.

\section{DISCUSSION}

The results from Experiment 1 indicate that medial striatal inactivation did not impair acquisition of a place discrimination, but did impair place learning when conditions demanded selecting a new spatial location and inhibit selecting a previously reinforced spatial location. Because temporary inactivation of the medial striatum produced a selective deficit during reversal learning, the findings suggest that the impairment is not due to changes in motivation or motor function, nor a general impairment in place learning. This pattern of results is similar to previous results demonstrating that lesions or temporary inactivation of the medial striatum produced a deficit in place, visual cue, or response reversal learning, as well as shifts between visual cue and response strategies (Kirby 1969; Livesey and Muter 1976; Kolb 1977; Pisa and Cyr 1990; Ragozzino et al. 2002a,b). Thus, the medial striatum may facilitate the flexible use of response patterns in various situations.

The place reversal-learning deficit produced by medial striatal inactivation led to an increase in regressive errors, but not perseverative errors. This pattern indicates that medial striatal inactivation did not impair the initial shift from the previously reinforced choice pattern, but increased reversions back to the previously reinforced spatial location as a rat began to learn the new, relevant choice pattern. This selective increase in regressive errors has also been observed following medial striatal inactivation in a response reversal-learning task, as well as shifts between a visual cue and response strategy (Ragozzino et al. 2002a,b). These findings suggest that the medial striatum is not critical for the initial inhibition of a previously learned strategy or generation of a new strategy, because there was no increase in perseveration, but may be critical for enabling the execution of effective strategies for a particular behavioral context by reinforcing the correct choice pattern when generated (Wise et al. 1996).

Unlike the medial striatum, temporary inactivation or lesions of the medial prefrontal cortex and orbital prefrontal cortex both produce behavioral flexibility impairments by increasing perseverative responses, but not regressive errors (Eichenbaum et al. 1983; Ragozzino et al. 1999, 2003; Dias and Aggleton 2000; Kim and Ragozzino 2003). Interestingly, both of these prefrontal cortex areas project to the medial striatum (Berendse et al. 1992). The dissociation in error patterns following medial striatal and prefrontal cortex inactivation suggests that these interconnected 

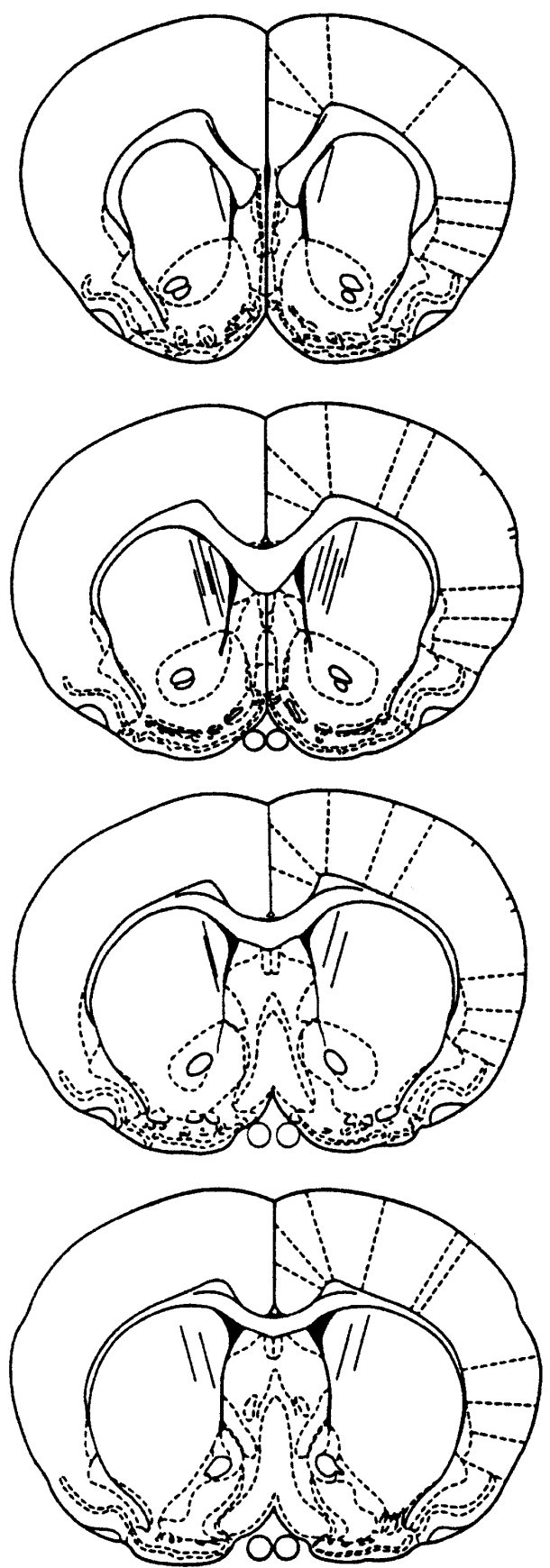

Figure 3 Placement of the microdialysis probes in the striatum for rats included in the behavioral and neurochemical analyses in Experiment 2. The length of the microdialysis probe was $2 \mathrm{~mm}$. Microdialysis probes were concentrated in the dorsomedial striatum ranging from 0.2-1.7 anterior to bregma. Rat brain sections were modified from the atlas of Paxinos and Watson (1996).

areas play complimentary roles as part of a larger neural system to enable the shifting of strategies under changing environmental demands.

Experiment 2 measured changes in ACh output during place acquisition and reversal learning. The combined techniques used to collect and measure ACh efflux are sensitive in detecting even small fluctuations in ACh output (Fadel et al. 2001; Chang and Gold 2003). The findings from Experiment 2 revealed that ACh efflux did not change compared with baseline levels at any point during the initial learning of a place discrimination. In contrast, a distinct pattern of ACh output occurred during place reversal learning. Specifically, ACh output did not change during the first test block, as rats spent a large portion of the period perseverating to the previously reinforced location, but ACh efflux increased significantly in the subsequent three test blocks, as rats were learning to choose the other spatial location. As rats showed a high level of accuracy over the last two blocks, ACh efflux was near basal levels. The selective elevation in ACh efflux during reversal learning is also consistent with a recent study demonstrating that the blockade of muscarinic cholinergic receptors in the medial striatum does not impair acquisition of a response discrimination, but selectively impairs response reversal learning by increasing regressive errors (Ragozzino et al. 2002b). Thus, ACh actions in the medial striatum may facilitate flexible adaptations that are mediated by muscarinic cholinergic receptors.

The pattern of change in ACh output during reversal learning has interesting parallels with the error pattern observed in reversal learning following bupivacaine treatment. Medial striatal inactivation impaired reversal learning, not by increasing perseveration, but by increasing regressive errors. However, almost all rats from this first study, including controls, showed some degree of perseveration during the initial trials of reversal learning. This was also true for rats in the second study, as indicated by an accuracy that was below chance during the first test block. Although, by the end of the test block, all of these rats began to choose the new correct location. No increase in ACh output was observed during the first test block when rats were predominantly perseverating. After perseveration had ceased in Experiment 1 , medial striatal inactivation prevented the continual inhibition of the previously relevant choice pattern, leading to a significant increase in regressive errors. In Experiment 2, only after perseveration had ceased and a rat was beginning to inhibit the previously relevant choice pattern and learn the new choice pattern, was a significant elevation in ACh output exhibited. This pattern of ACh output suggests that cholinergic interneurons from the medial striatum are activated when environmental conditions change, demanding the continual inhibition of a previously relevant choice pattern while learning a new choice pattern.

Because ACh output did not increase during acquisition, the increase observed during reversal learning can not be attributed to navigating in the maze and/or the consumption of cereal pieces. Furthermore, the ACh output increase is unlikely due to the amount of reinforcement, because a rat who was at chance levels during acquisition did not exhibit an increase in ACh output, but did show an increase in ACh output when a similar level of accuracy was achieved during reversal learning. In a related manner, the increase in ACh output also cannot be attributed to a "frustration" effect, because the largest increase was observed when accuracy continued to improve (test blocks 2-4) and not when accuracy was the lowest (test block 1 ), the time when "frustration" would likely be highest. In addition, it is unlikely that the elevated ACh efflux was just a delayed response following "frustration," because on the last day of habituation, rats were reinforced almost every time when entering an arm, then on the following day, in acquisition testing, rats were reinforced in approximately half of the trials in the first test block, but at no point during acquisition was there an elevation of ACh efflux.

An alternative explanation for the increase in ACh efflux during reversal learning is that rats initially used an egocentric response strategy, for example, always turn right, and the expression of an egocentric response strategy resulted in elevated ACh output, but not the actual behavioral switching. The results from previous studies suggest that the striatum, as a whole, may be 
A

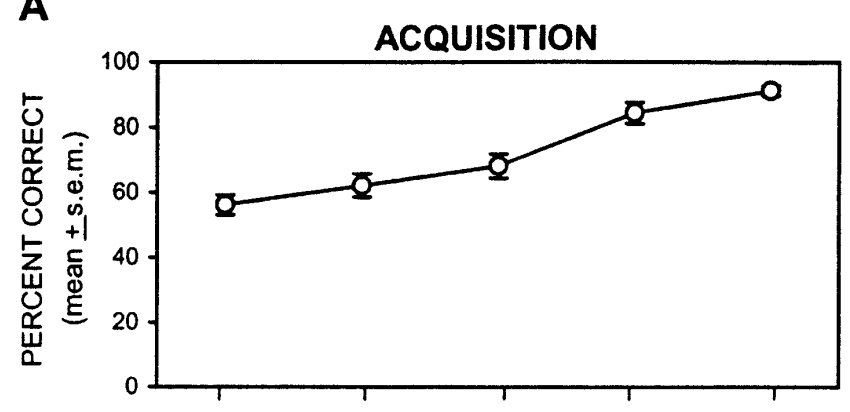

B

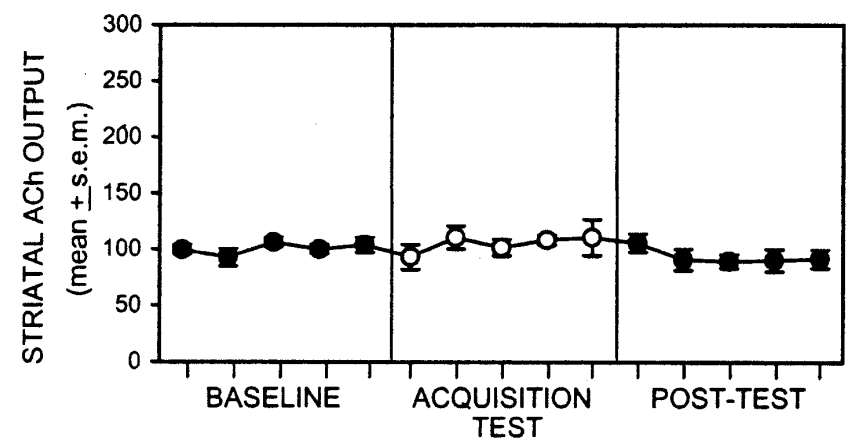

Figure $4(A)$ Mean percent correct during place acquisition testing. Each rat was tested for five 6-min blocks. The total number of trials completed in a block ranged from 8-14. Rats performed slightly above chance levels at the first test block and improved to $>90 \%$ accuracy by the last test block. $(B)$ Effect of place acquisition testing on medial striatal ACh output. ACh output during place acquisition testing did not change compared with baseline levels. ACh output following behavioral testing was also comparable with that during baseline collection.

critical for egocentric response learning (Potegal 1969; Cook and Kesner 1988; Kesner et al. 1993). Furthermore, measuring ACh output from the dorsolateral striatum during a place-response task, Chang and Gold (2003) found that ACh output selectively increased after extensive testing when rats predominantly manifested an egocentric response strategy. In the present study, some rats appeared to be using an egocentric response strategy during the test blocks in which ACh output was elevated, but there was no difference in ACh output between the rats who appeared to express an egocentric response strategy and those rats who did not. Thus, the elevated ACh output during reversal learning cannot be explained by the expression of an egocentric response strategy.

The present findings, indicating that ACh actions in the medial striatum facilitate the shifting of choice patterns, and the results by Chang and Gold (2003) showing that ACh actions in the lateral striatum support the expression of an egocentric response strategy, suggest that ACh actions in the striatum contribute to multiple functions that may be defined by striatal subregion. Taken together, the results are consistent with accumulating evidence that the dorsomedial and dorsolateral striatum contribute differentially to various learning and memory processes (Brown and Robbins 1989; Pisa and Cyr 1990; Brasted et al. 1999; Devan et al. 1999).

The finding that rats use various strategies in attempting to learn a new task have been reported previously (Krechevsky 1938; Whishaw and Petrie 1988). One idea is that during the learning or presolution phase, a rat may try multiple strategies, from which the correct one is eventually chosen (Krechevsky 1938). We have observed in several studies that rats often at- tempt various inappropriate strategies before selecting the appropriate strategy in a specific context (Ragozzino 2002; M.E. Ragozzino and K.E. Ragozzino, unpubl.). However, despite individual differences among rats, manipulations of the medial striatum have reliably produced distinct patterns of errors during tests of behavioral flexibility (Ragozzino et al. 2002a,b). The pattern of increase in medial striatal ACh efflux during reversal learning is consistent with the idea that cholinergic activity in this region facilitates the learning of a new choice pattern and the inhibition of an old choice pattern under changing environmental contingencies.

How might cholinergic activity modify striatal output to influence shifts in response patterns? Graybiel (1998) has proposed that cholinergic interneurons modulate corticostriatal activity in different clusters of matrisomes, which leads to a recoding of corticostriatal information. The differential pattern of activation in this circuitry may lead to long-term plastic changes, ultimately producing changes in response selection. Whereas this idea has been proposed for the mechanisms underlying stimulus-response learning in the striatum, a similar mechanism may occur in the medial striatum to facilitate the switching of choice patterns under changing environmental demands.

\section{MATERIALS AND METHODS}

\section{Subjects}

Male Long-Evans rats (Charles Rivers), weighing between 350 and $375 \mathrm{gm}$ at the beginning of the experiment, served as subjects. Rats were housed individually in plastic cages $(26.5 \mathrm{~cm}$ wide $\times 50 \mathrm{~cm}$ long $\times 20 \mathrm{~cm}$ high) located in a temperature-controlled room. Subjects were kept on a 12-h light/dark cycle (lights on at 7 a.m.). All rats were food restricted to maintain their weight at $90 \%$ of their ad libitum weight with free access to water throughout the experiment.

\section{Apparatus}

A four-arm cross-maze made of $0.6 \mathrm{~cm}$ thick black plastic was used for all behavioral testing. The maze was placed on a table that was $72 \mathrm{~cm}$ above the floor. Each arm was $55 \mathrm{~cm}$ long $\times 10$ $\mathrm{cm}$ wide. The height of the arm walls was $15.0 \mathrm{~cm}$. Each arm contained a food well $(3.2 \mathrm{~cm}$ diameter $\times 1.6 \mathrm{~cm}$ high) that was $3 \mathrm{~cm}$ away from the end wall. Each food-well hole was $2.3 \mathrm{~cm}$ in diameter and $1.6 \mathrm{~cm}$ deep.

\section{Surgery}

Each rat received stereotaxic surgery to bilaterally implant cannula into the medial striatum. A rat was first injected with atropine sulfate $(0.2 \mathrm{~mL}$ of a $250 \mu \mathrm{g} / \mathrm{mL}$ solution, i.p.). Ten minutes after the injection of atropine, the general anesthetic, sodium pentobarbital (50 mg/kg, i.p.) was administered. Subsequently, a rat was placed on the stereotaxic frame, and the incisor bar was positioned to $3.3 \pm 0.4$ below horizontal zero to equal the height of bregma and $\lambda$. A midsaggital incision was made and the scalp retracted. In Experiment 1, each rat was implanted bilaterally with an 8-mm stainless-steel guide cannula (Plastics One) into the dorsomedial striatum. The stereotaxic coordinates were $1.1 \mathrm{~mm}$ anterior to bregma, $\pm 2.8 \mathrm{~mm}$ lateral to the midline and $3.5 \mathrm{~mm}$ ventral to dura. The cannulae were implanted at a $10^{\circ}$ angle. In Experiment 2, each rat was implanted bilaterally with a 10-mm guide cannula (BAS). The stereotaxic coordinates were $1.1 \mathrm{~mm}$ anterior to bregma, \pm 3.0 lateral to the midline and 3.3 ventral to dura. The cannulae were implanted at a $15^{\circ}$ angle. In both experiments, four jeweler's screws were positioned in the skull surrounding the cannulae. The cannulae were secured in place with dental acrylic (Stoelting). Stylets were secured in the guide cannulae after the dental acrylic dried. Following surgery, rats received $6 \mathrm{cc}$ of saline (s.c.). Each rat was fed rat-ground rat chow with sugar that was mixed in water for $1 \mathrm{~d}$.

\section{Learning \& Memory}

www.learnmem.org 
A

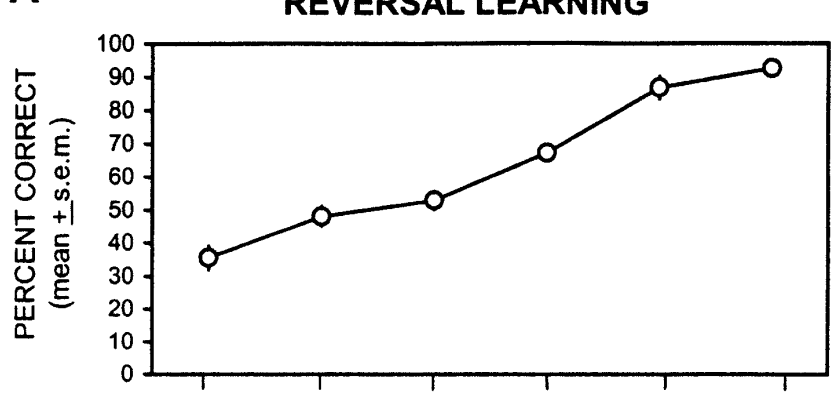

B

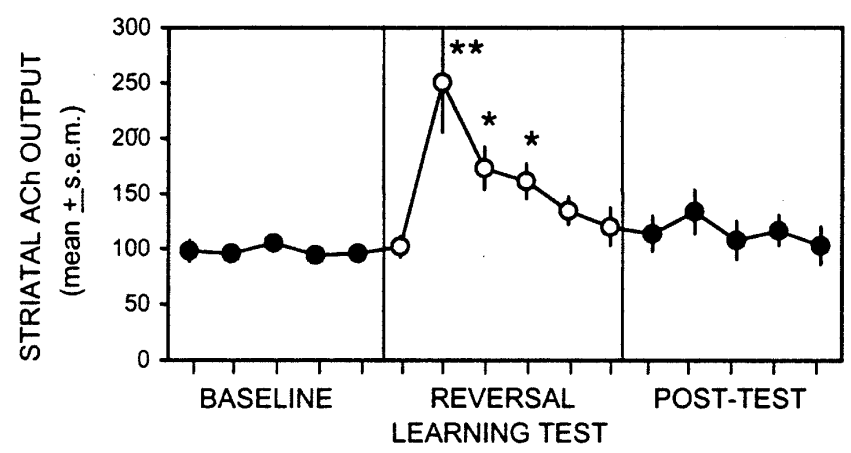

Figure $5(A)$ Mean percent correct during place reversal learning. Each rat was tested for six 6-min blocks. The total number of trials completed in a block ranged from 9-14. Rats started below chance levels during the first test block, but improved across each test block, obtaining $>90 \%$ accuracy by the last test block. (B) Effect of place reversal learning testing on medial striatal ACh output. ACh output did not change during the first test block compared with baseline levels. ACh output significantly increased above baseline levels during test blocks 2-4. ACh output during test blocks 5 and 6 was not significantly different from baseline levels. $\left.{ }^{* *}\right) P<0.01 ;\left(^{*}\right) P<0.05$.

\section{Microinfusion}

In Experiment 1, bilateral infusions into the medial striatum were made through an inner cannula (28 gauge) that extended $1 \mathrm{~mm}$ below the guide cannula. The inner cannula was attached to a polyethylene tube (PE-20) connected to a $10 \mu \mathrm{L}$ Hamilton syringe. The syringe was driven by a microinfusion pump (74900 Series, Cole-Parmer). Solutions were infused at a rate of $0.5 \mu \mathrm{L}$ per $2 \mathrm{~min}$. The total volume injected on each side was $0.5 \mu \mathrm{L}$. Following the injection, the inner cannula remained in the guide cannula for $1 \mathrm{~min}$ to allow for diffusion. Rats received either saline or the local anesthetic, bupivacaine, at a $2 \%$ concentration. The same concentration has been used in previous studies that inactivated specific brain regions to examine the effects on learning and memory (Ragozzino et al. 2002b, 2003).

\section{Microdialysis}

In Experiment 2, a 2-mm dialysis probe was inserted through the guide cannula on one side. The dialysis probe was connected to plastic tubing. The plastic tubing was attached to a liquid swivel. Plastic tubing was attached to a microinfusion pump, which connected to the liquid swivel. The liquid swivel was connected to a balance arm, which was attached to a metal bar that was permanently fixed to the ceiling directly above the maze. The dialysis probe was perfused continuously at a rate of $2.0 \mu \mathrm{L} / \mathrm{min}$ with artificial cerebrospinal fluid. The artificial cerebrospinal fluid contained $128 \mathrm{mM} \mathrm{NaCl}, 2.5 \mathrm{nM} \mathrm{KCl}, 1.3 \mathrm{mM} \mathrm{Ca} \mathrm{Cl}, 2.1 \mathrm{mM}$ $\mathrm{Mg} \mathrm{Cl}_{2}$, and $3.3 \mathrm{mM}$ glucose. The solution was brought to a $\mathrm{pH}$ of 7.4 by $\mathrm{NaOH}$. To reliably detect ACh levels in the dialysate, the reversible acetylcholinesterase inhibitor, neostigmine bromide $(0.1 \mu \mathrm{M})$ was added to the artificial cerebrospinal fluid.

\section{Habituation}

A similar habituation procedure was used in both experiments. One week after surgery, habituation in the cross-maze was begun. On the first day of habituation, three half pieces of Froot Loops cereal (Kelloggs) were placed in each arm of the maze. Two pieces were placed in each food well, and one was placed outside of the food well. A rat was placed in the maze and allowed to explore each arm and consume cereal pieces. If a rat consumed all cereal pieces before 15 min elapsed, then the rat was placed in a holding chamber, the food wells were reloaded with cereal pieces, and the rat was placed back in the maze. Once 15 min elapsed, the session was terminated.

On subsequent habituation days, only two half pieces of cereal were placed inside each well. After eating two half pieces of cereal from any food well, a rat was picked up and placed in a different start arm. This acclimated the rat to being picked up in the maze after consuming cereal, as would occur in the test procedure. This procedure was continued until a rat completed four trials in $15 \mathrm{~min}$ or less across 2 consecutive days. On the last day of habituation, the maze was arranged such that a black plastic block $(9 \mathrm{~cm}$ wide $\times 13 \mathrm{~cm}$ high $\times 1.0 \mathrm{~cm}$ thick) was placed at the center entrance of one arm, preventing entry into that arm. This gave the maze a T-shape. A rat was started from the stem arm and allowed to turn left or right to obtain a half piece of cereal. After this initial choice, the rat was picked up and placed back into the stem arm and allowed to make a second choice. If the rat chose the same arm as the initial choice, it was returned to the stem arm until the it chose the other arm. After the rat chose both arms, it was placed back in the holding cage, the block was moved to a different location, and the two choice arms baited. This procedure was continued for seven trials.

Following the last habituation session, the stylets of a rat were removed and either an injection needle (Experiment 1 ) or a microdialysis probe (Experiment 2) was inserted through the guide cannula for $1 \mathrm{~min}$. This was done to prevent clogging of the microinfusion or dialysis perfusion on test days. The habituation procedure lasted 4-11 d. In Experiment 1, rats were assigned pseudorandomly to the different treatment groups to match the amount of habituation sessions among the groups.

\section{Place Discrimination Test}

In Experiment 1, rats were tested on the acquisition and reversal learning of a place discrimination across 2 consecutive days. Rats were started randomly from two different arms, opposite each other, and had to enter the same arm to receive a half piece of Froot Loops cereal. Between trials, a rat was placed in a roundbottom plastic bowl (35 $\mathrm{cm}$ high $\times 40 \mathrm{~cm}$ diameter), which sat next to the maze. Subsequently, the maze arms were wiped down by a sponge moistened with an ammonium chloride solution. The intertrial interval was $\sim 15 \mathrm{sec}$. To minimize the use of intramaze cues, every four trials, the maze was turned $90^{\circ}$ clockwise relative to the experimenter. A rat reached criterion when it made 10 consecutive correct choices. This is a similar criterion as used in previous studies (Ragozzino et al. 2002a,b). On the second day of testing (reversal learning), a rat was required to enter the opposite arm that was reinforced during acquisition. Again, the rat reached criterion when it made 10 consecutive correct choices.

In Experiment 1, the error pattern during reversal learning was analyzed to determine whether temporary inactivation affected perseveration or reversions back to the previously correct place choice after perseveration had ceased. Perseveration involved continuing to enter the same arm that was reinforced during the acquisition phase. Perseveration was defined as entering the incorrect arm in three or more trials in consecutive blocks of four trials each. This is a similar criterion as used in previous studies (Dias and Aggleton 2000; Ragozzino 2002; Ragozzino et al. 2002a,b). Once a rat made less than three errors in a block the first time, all subsequent errors were no longer counted as perseverative errors. When perseveration ceased, as defined above, the number of errors was counted when a rat reverted back to the previously correct choice. These errors are referred to 
as regressive errors. This allowed a measure of the ability to maintain or learn a new choice pattern after the initial shift.

Five minutes prior to each test session, rats received a microinfusion. Each rat was pseudorandomly assigned to one of three treatment groups to match the amount of habituation sessions among the groups. Group assignment was determined by the treatment administered during each phase, (1) acquisitionsaline and reversal learning-saline $(n=6) ;(2)$ acquisition-saline and reversal learning-2\% bupivacaine $(n=6)$; and (3) acquisition-2\% bupivacaine and reversal learning-saline $(n=6)$.

In Experiment 2, place discrimination testing was combined with microdialysis collection. A total of 10 rats were used in this study. Prior to behavioral testing, a rat was placed in a roundbottom plastic bowl, and a probe was placed in one hemisphere. The group was counterbalanced, such that half of the rats had a probe in the left hemisphere during place acquisition, and half of the rats had a probe in the right hemisphere during place acquisition. The perfusate collected during the first $60 \mathrm{~min}$ was not analyzed, to allow equilibration between the brain tissue and perfusion solution before sampling. Subsequently, five samples were collected at 6-min intervals that served as baseline rates for ACh output. Following baseline collection, a rat was placed in the maze for acquisition testing. A similar test procedure was used as in Experiment 1, except that each rat was tested for a total of 30 min and not until a rat achieved a certain learning criterion. This allowed collection of five microdialysis samples during behavioral testing. A rat's behavioral performance was separated into 6-min blocks, which corresponded with the collection of microdialysis samples. For each 6-min block, a percent correct score was determined by calculating the number of trials a rat chose the correct arm divided by the total number of trials for that block. After behavioral testing, the rat was returned to the plastic bowl and five posttest samples were collected.

On the following day, rats were tested on place reversal learning. A probe was placed in the opposite hemisphere, as on place acquisition. A similar procedure was used as during place acquisition. However, during reversal-learning testing, when a rat was required to enter the opposite arm, testing lasted $36 \mathrm{~min}$. In this behavioral testing phase, six microdialysis samples were collected. Again, a percent correct score was calculated for each 6-min block, and behavioral testing was followed by collection of five samples while a rat remained in the plastic bowl.

\section{ACh Assay}

Samples $(10 \mu \mathrm{L})$ were assayed for ACh using high-pressure liquid chromatography with electrochemical detection. Samples were loaded on a microbore analytical column for separation of ACh and choline. Following separation, an enzymatic post-column reactor containing acetylcholinesterase and choline oxidase converted ACh to choline and acetate and choline to betaine and hydrogen peroxide. Stoichiometric quantities of hydrogen peroxide were produced from the breakdown of $\mathrm{ACh}$ and choline. The hydrogen peroxide was further broken down and detected by a glassy carbon-wired electrode coated with horseradish peroxidase operated at $+100 \mathrm{mV}$ versus an $\mathrm{Ag} / \mathrm{AgCl}$ reference electrode (Huang et al. 1995). The mobile phase containing $50 \mathrm{mM}$ $\mathrm{Na}_{2} \mathrm{HPO}_{4}, 0.3 \mathrm{mM}$ EDTA, and $0.005 \%$ ProClin (to prevent bacterial growth) was delivered at a rate of $100 \mu \mathrm{L} / \mathrm{min}$ by a solvent delivery system. ACh peaks were quantified by comparison with peak heights of ACh standard solutions. The detection limit was $10 \mathrm{fmole}$, and the assay was completed in $12 \mathrm{~min}$.

\section{Histology}

After completion of behavioral testing, each rat received a lethal dose of sodium pentobarbital. In Experiment 1, each rat received a $0.5-\mu \mathrm{L}$ injection of $2.5 \%$ Chicago blue stain through each guide cannula to highlight the approximate spread of the intracranial injection as in previous studies (Ragozzino et al. 2002a,b). In Experiment 2, a probe dipped in $2.5 \%$ Chicago blue stain was inserted in each guide cannula to highlight the location of the probe. All rats were perfused intracardially with $0.9 \%$ phosphate buffered saline, followed by a $4 \%$ formaldehyde solution. Brains were removed and stored in a $4 \%$ formaldehyde solution. The brains were frozen and cut in coronal sections $(40 \mu \mathrm{m})$ on a cryostat. The brain sections were mounted on slides, dried, and examined to determine the spread of the stain. Subsequently, the brain sections were stained with cresyl violet to assess the location of the cannula tips or probes.

\section{Statistical Analysis}

In Experiment 1, a one-way analysis of variance (ANOVA) was used to determine whether the groups differed on the number of trials to criterion in the acquisition and reversal-learning phases. Separate ANOVA tests were used to examine perseverative and regressive errors among the groups.

In Experiment 2, the microdialysis data were analyzed by converting the raw values to percentages from each subject's baseline output. The baseline output was calculated from the mean of the first five samples for each subject. The percent values were analyzed by a repeated measures ANOVA. Dunnett's test was applied to compare specific samples with the last baseline value.

A repeated-measures ANOVA was used to analyze the percent correct scores across blocks for place acquisition and reversal-learning testing.

\section{ACKNOWLEDGMENTS}

This research was supported by NIH grant MH61889 and a Campus Review Board grant from the University of Illinois at Chicago.

The publication costs of this article were defrayed in part by payment of page charges. This article must therefore be hereby marked "advertisement" in accordance with 18 USC section 1734 solely to indicate this fact.

\section{REFERENCES}

Aosaki, T., Tsubokawa, H., Ishida, A., Watanabe, K., Graybiel, A.M., and Kimura, M. 1994. Responses of tonically active neurons in the primate's striatum undergo systematic changes during behavioral sensorimotor conditioning. J. Neurosci. 14: 3969-3984.

Aosaki, T., Kimura, M., and Graybiel, A.M. 1995. Temporal and spatial characteristics of tonically active neurons of the primate's striatum. I. Neurophysiol. 73: 1234-1252.

Apicella, P., Schultz, W., and Scarnati, E. 1991. Responses of tonically discharging neurons of monkey striatum respond to preparatory and rewarding stimuli. Exp. Brain Res. 116: 456-466.

Berendse, H.W., Galis-de Graaf, Y., and Groenewegen, H.J. 1992. Topographical organization and relationship with ventral striatal compartments of prefrontal corticostriatal projections in the rat. J. Comp. Neurol. 316: 314-347.

Bolam, J.P., Ingham, C.A., and Smith, A.D. 1984. The section-Golgi-impregnation procedure. 3. Combination of Golgi impregnation with enzyme histochemistry and electron microscopy to characterize acetylcholinesterase-containing neurons in the rat neostriatum. Neuroscience 12: 687-709.

Brasted, P.J., Robbins, T.W., and Dunnett, S.B. 1999. Distinct roles for striatal subregions in mediating response processing revealed by focal excitotoxic lesions. Behav. Neurosci. 113: 253-264.

Brown, V.J. and Robbins, T.W. 1989. Elementary processes of response selection mediated by distinct regions of the striatum. J. Neurosci. 9: $3760-3765$.

Chang, Q. and Gold, P.E. 2003. Switching memory systems during learning: Changes in brain acetylcholine release in the hippocampus and striatum in rats. J. Neurosci. 23: 3001-3005.

Cook, D. and Kesner, R.P. 1988. Caudate nucleus and memory for egocentric localization. Behav. Neural Biol. 49: 332-343.

Devan, B.D., McDonald, R.J., and White, N.M. 1999. Effects of medial and lateral caudate-putamen lesions on place- and cue-guided behaviors in the water maze: Relation to thigmotaxis. Behav. Brain Res. 100: 5-14.

Dias, R. and Aggleton, J.P. 2000. Effects of selective excitotoxic prefrontal lesions on acquisition of nonmatching- and matching-to-place in the T-maze in the rat: Differential involvement of the prelimbic-infralimbic and anterior cingulate cortices in providing behavioural flexibility. Eur. J. Neurosci. 12: 4457-4466.

Dunnett, S.B. and Iversen, S.D. 1982. Neurotoxic lesions of ventrolateral but not anteromedial neostriatum in rats impair differential reinforcement of low rates (DRL) performance. Behav. Brain Res. 
6: $213-226$.

Dunnett, S.B., Nathwani, F., and Brasted, P.J. 1999. Medial prefrontal and neostriatal lesions disrupt performance in an operant delayed alternation task in rats. Behav. Brain Res. 106: $13-28$.

Eagle, D.M., Humby, T., Dunnett, S.B., and Robbins, T.W. 1999. Effects of regional striatal lesions on motor, motivational and executive aspects of progressive-ratio performance in rats. Behav. Neurosci. 113: 718-731.

Eichenbaum, H., Clegg, R.A., and Feeley, A. 1983. Reexamination of functional subdivisions of the rodent prefrontal cortex. Exp. Neurol. 79: 434-451.

Fadel, J., Sarter, M., and Bruno, J.P. 2001. Basal forebrain glutamatergic modulation of cortical acetylcholine release. Synapse 39: 201-212.

Graybiel, A.M. 1998. The basal ganglia and chunking of action repertoires. Neurobiol. Learn. Mem. 70: 119-136.

Huang, T., Yang, L., Gitzen, J., Kissinger, P.T., Vreeke, M., and Heller, A. 1995. Detection of basal acetylcholine in rat brain microdialysate. J. Chromatography 670: 323-327.

Kawaguchi, Y. 1993. Physiological, morphological and histochemical characterization of three classes of interneurons in rat neostriatum. I. Neurosci. 13: 4908-4923.

Kesner, R.P., Bolland, B.L., and Dakis, M. 1993. Memory for spatial locations, motor responses, and objects: Triple dissociation among the hippocampus, caudate nucleus, and extrastriate visual cortex. Exp. Brain Res. 93: 462-470.

Kim, J. and Ragozzino, M.E. 2003. The role of the rat orbital prefrontal cortex in odor reversal learning. Soc. Neurosci. Abst. (in press).

Kirkby, R.J. 1969. Caudate nucleus lesions and perseverative behavior. Physiol. Behav. 4: 451-454.

Kolb, B. 1977. Studies on the caudate-putamen and the dorsomedial thalamic nucleus of the rat: Implications for mammalian frontal-lobe functions. Physiol. Behav. 18: 237-244.

Krechevsky, I. 1938. A study of continuity of the problem-solving process. Psych. Rev. 45: 107-133.

Levy, R., Friedman, H.R., Davachi, L., and Goldman-Rakic, P.S. 1997. Differential activation of the caudate nucleus in primates performing spatial and nonspatial working memory tasks. J. Neurosci. 17: $3870-3882$.

Livesey, P.J. and Muter, V. 1976. Functional differentiation within the neostriatum of the rat using electrical (blocking) stimulation during discrimination learning. J. Comp. Physiol. Psych. 90: 203-211.

Mizumori, S.J.Y., Ragozzino, K.E., and Cooper, B.G. 2000. Location and head direction representation in the dorsal striatum of rats. Psychobiology 28: 441-462.

Paxinos, G. and Watson, C. 1996. The rat brain in stereotaxic coordinates, $3^{\text {rd }}$ Ed. Academic Press, Sydney, Austrailia.

Pisa, M. and Cyr, J. 1990. Regionally selective roles of the rat's striatum in modality specific discrimination learning and forelimb reaching. Behav. Brain. Res. 37: 281-292.

Potegal, M. 1969. Role of the caudate nucleus in spatial orientation of rats. J. Comp. Physiol. Psych. 69: 756-764.

Ragozzino, M.E. 2002. The effects of dopamine $\mathrm{D}_{1}$ receptor blockade in the prelimbic-infralimbic areas on behavioral flexibility. Learn. Mem. 9: $18-28$.

Ragozzino, M.E., Detrick, S., and Kesner, R.P. 1999. Involvement of the prelimbic-infralimbic areas of the rodent prefrontal cortex in behavioral flexibility for place and response learning. J. Neurosci. 19: $4585-4594$

Ragozzino, M.E., Ragozzino, K.E., Mizumori, S.J.Y., and Kesner, R.P. 2002a. The role of the dorsomedial striatum in behavioral flexibility for response and visual cue discrimination learning. Behav. Neurosci. 116: $105-115$

Ragozzino, M.E., Jih, J., and Tzavos, A. 2002b. Involvement of the dorsomedial striatum in behavioral flexibility: Role of muscarinic cholinergic receptors. Brain. Res. 953: 205-214.

Ragozzino, M.E., Kim, J., Hassert, D., Minniti, N., and Kiang C. 2003. The contribution of the rat prelimbic-infralimbic areas to different forms of task switching. Behav. Neurosci. (in press).

Ravel, S., Sardo, P., Legallet, E., and Apicella, P. 2001. Reward unpredictability inside and outside of a task context as determinant of the responses of tonically active neurons in the monkey striatum. I. Neurosci. 21: 5730-5739.

Smith-Roe, S.L., Sadeghian, K., and Kelley, A.E. 1999. Spatial learning and performance in the radial arm maze is impaired after N-methyl-D-aspartate (NMDA) receptor blockade in striatal subregions. Behav. Neurosci. 113: 703-717.

Thompson, W.G., Guilford, M.O., and Hicks, L.H. 1980. Effects of caudate and cortical lesions on place and response learning in rats. Physiol. Psych. 8: 473-479.

Whishaw, I.Q. and Petrie, B.F. 1988. Cholingergic blockade in the rat impairs strategy selection, but not learning and retention of nonspatial visual discrimination problems in a swimming pool. Behav. Neurosci. 102: 662-677.

Whishaw, I.Q., Mittleman, G., Bunch, S.T., and Dunnett, S.B. 1987. Impairments in the acquisition, retention and selection of spatial navigation strategies after medial caudate-putamen lesions in rats. Behav. Brain. Res. 24: 125-138.

Wilson, C.J., Chang, H.T., and Kitai, S.T. 1990. Firing patterns and synaptic potentials of identified giant aspiny interneurons in the rat neostriatum. J. Neurosci. 10: 508-519.

Wise, S.P., Murray, E.A., and Gerfen, C.R. 1996. The frontal cortex-basal ganglia system in primates. Crit. Rev. Neurobiol. 10: 317-356.

Woolf, N.J. and Butcher, L.L. 1981. Cholinergic neurons in the caudate-putamen complex proper are intrinsically organized: A combined Evans blue and acetylcholinesterase analysis. Brain. Res. Bull. 7: 487-507.

Received June 25, 2003; accepted in revised form August 21, 2003. 


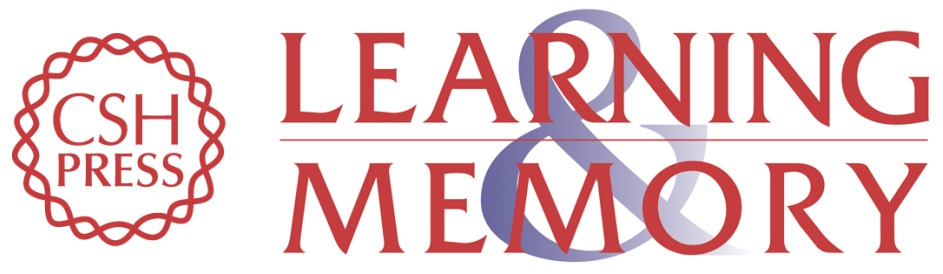

\section{Dynamic Changes in Acetylcholine Output in the Medial Striatum During Place Reversal Learning}

Michael E. Ragozzino and Daniel Choi

Learn. Mem. 2004, 11:

Access the most recent version at doi:10.1101/lm.65404

References This article cites 40 articles, 9 of which can be accessed free at: http://learnmem.cshlp.org/content/11/1/70.full.html\#ref-list-1

License

Email Alerting Receive free email alerts when new articles cite this article - sign up in the box at the Service top right corner of the article or click here. 